
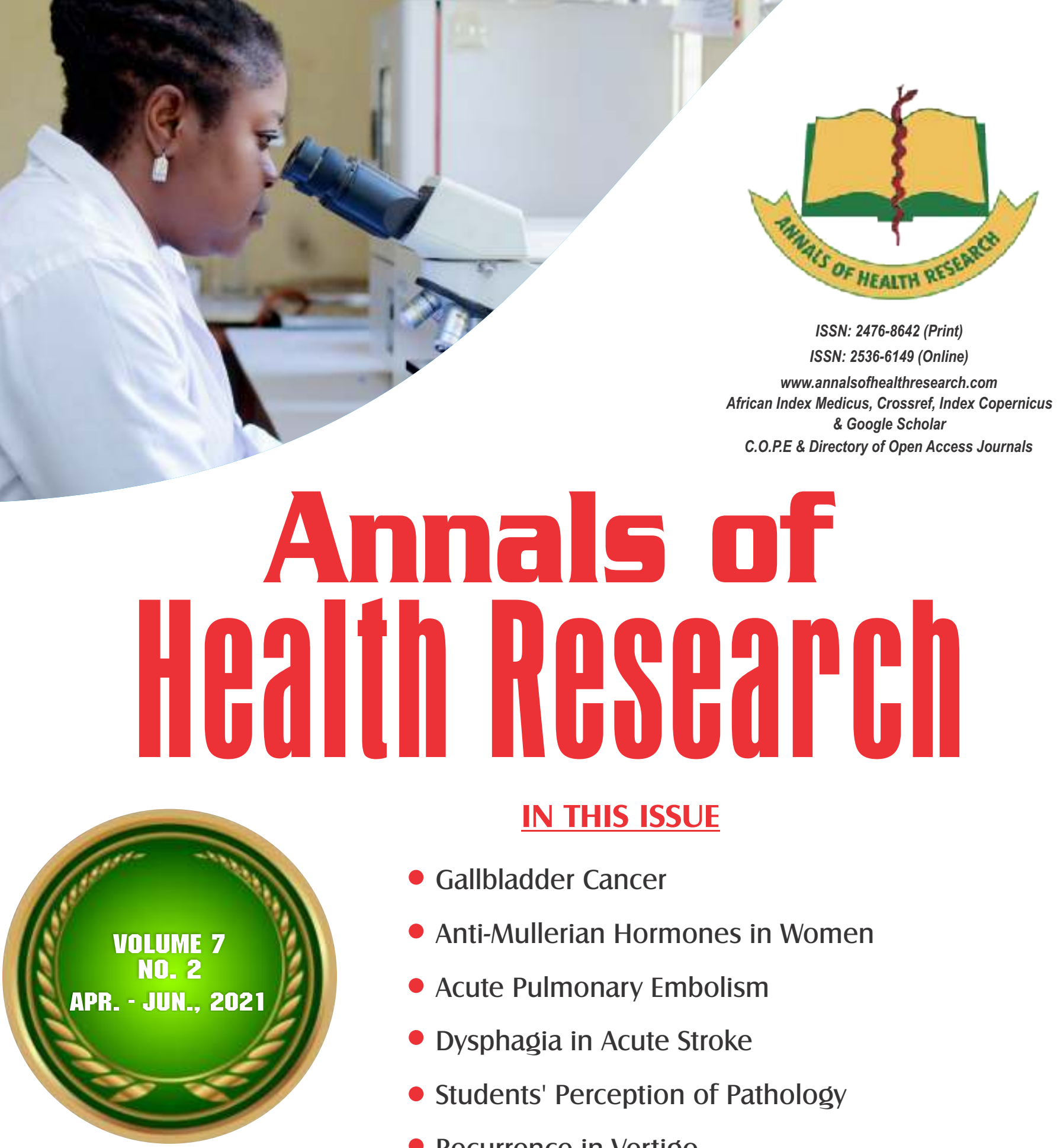

IN THIS ISSUE

- Gallbladder Cancer

- Anti-Mullerian Hormones in Women

- Acute Pulmonary Embolism

- Dysphagia in Acute Stroke

- Students' Perception of Pathology

- Recurrence in Vertigo

- Electroencephalography in Epilepsy

- Health-seeking Behaviour

- Breastfeeding and Nutritional Status

- Osteosarcoma

PUBLISHED BY THE MEDICAL AND DENTAL CONSULTANTS ASSOCIATION OF NIGERIA, OOUTH, SAGAMU, NIGERIA. 


\title{
Perception of Preclinical Medical Students About Pathology Subject and the Teaching Methods in an Indian Medical College Sood S*, Gulia SP
}

Department of Pathology, Adesh Medical College and Hospital, Mohri, Shahbad (M), Kurukshetra, India

*Correspondence: Dr S Sood, Department of Pathology, Adesh Medical College and Hospital, Mohri, Shahbad
(M), Kurukshetra, India. E-mail: dr.samriddhi.sood@gmail.com; ORCID - https://orcid.org/0000-0001-5643-8851.

\begin{abstract}
Background: Pathology is a key subject at the pre-clinical stage of medical training. Objectives: To determine the perception of second-year MBBS (preclinical) students regarding Pathology as a subject and the effectiveness of various teaching, learning and assessment methods.

Methods: This cross-sectional study was carried out on 145 randomly selected, second-year MBBS students, appearing for their Phase II final university exams. A predesigned questionnaire with questions about students' perception of pathology was administered to the students. The questionnaire also assessed the various teaching-learning methods currently used by the faculty. The students were also requested to make suggestions regarding the modifications needed in the teaching methods.

Results: A total of 145 out of 150 regular-batch students participated in the study. One hundred (68.9\%) regarded pathology as an interesting subject; $131(90.3 \%)$ felt pathology acts as a bridge between paraclinical and clinical branches while 107 (73.8\%) found blackboard teaching more effective.

Conclusion: The study revealed that the preclinical medical students showed a favourable predisposition towards pathology as a subject while highlighting areas that need to be addressed for more effective teaching and improved learning towards producing better medical professionals.
\end{abstract}

Keywords: Medical curriculum, Medical students, Pathology, Perception, Preclinical training, Teaching methods.

\section{Introduction}

Pathology is one of the core subjects in the medical curriculum and it is ever-expanding. Pathology provides the knowledge of alteration of the physiological or normal conditions and aetiology of various diseases. This basic knowledge. helps with the understanding of the pathogenesis of diseases, structural alterations of cells (morphologic changes), and clinical manifestations forming the basis of all diagnosis and therapy. Pathology bridges the gap between the basic medical sciences and clinical medicine; this is important as a proper understanding of pathological processes is vitally important for medical practice. [1] Horizontal and vertical integrations also play important roles in building the clinical knowledge of students. Rafique [2] 
also opined that integrated teaching is effective in enhancing the skill of clinicopathological correlation and thus, helps to improve the cognitive and psychomotor domains of the students. It is a known fact that periodical review of the teaching program at regular intervals will help in improving the quality of teachinglearning methods in use to improve the standard of medical education. [3]

Pathology also plays an important role in clinical practice. Blood tests have an important role in the early diagnosis of diseases, considering the information such tests make available to physicians regarding pathological processes. Another relevance is the role of biomarkers in providing information regarding the nature of diseases; an example is pneumonia, where the physician can determine whether a disease is bacterial or due to other aetiologies by analysing the results of blood tests. [3] The recent change in the treatment of COVID-19 following the discovery of coagulopathy at autopsy (in a disease initially thought to be due to pneumonia), further highlights the role of pathology in clinical practice. Autopsy findings are also crucial to a better understanding of how infections affect the human body, similar to how these findings are important to understanding other infectious diseases. [4-5] Histopathological evidence of damage to the surface layers of airway epithelial cells and massive lung involvement with diffuse alveolar damage (DAD) and microvascular thrombi have been reported in the disease. [6] Comparison of haematological parameters between mild and severe cases of COVID-19 showed significant differences in interleukin-6 (IL-6), D-Dimer, glucose (GLU), thrombin time (TT), fibrinogen (FIB) and C-Reactive Protein (CRP). [7] Fan et al. [8] also analysed the haematological indices of COVID-19 infected patients between the intensive care unit (ICU) and non-ICU patients.
There are different branches in Pathology; these include haematology, blood banking, histopathology and cytology. The haematology section deals with the interpretation of peripheral blood smear with special reference to anaemias and leukaemias. Similarly, the cytology section includes observation of Fine Needle Aspirates for Cytology (FNACs), ultrasound-guided FNACs, Giemsa staining and pap staining whereas the histopathology section includes tissue processing and gross specimen identification. In blood banking, students are taught about donor selection criteria, donor bleeding and crossmatching as well as rational use of blood components.

Various teaching-learning methods such as integrated, system-based and problem-based learning approaches are in use. Some of the methods of teaching pathology subject include didactic lectures, museum sessions, PBL (Problem-based learning), DSL (Directed selflearning) and SDL (Self-directed learning) packages. Museum sessions are conducted with Powerpoint slide shows of images obtained from available websites. Histopathology slides demonstration is done using virtual microscopy as well as hands-on light microscopic study, displayed laminated sheets of pathologic images (picture plates) and traditional way of using the demonstration of potted morbid specimens. [9]

In most medical schools, practical exercises are an integral part of pathology course works and the assessment of these practical exercises is important. In the assessment of medical subjects, the extensively applied Objective Structured Practical Examination (OSPE) is popularly used. [5] Other methods of assessment include the Objective Structured Clinical Examination (OSCE) and the Multiple Choice Questions (MCQ). The inclusion of MCQs in written examinations was suggested at the National Consultative meeting on review of pharmacology curriculum. [6] Buzz groups and 
one-minute preceptor also assist students with good ranks in the online postgraduate entrance examinations along with improvement of their clinical knowledge and communication skills.

Recent assessment methods are attempting to increase the inter-relationship between what students need to learn and the knowledge they are expected to display. [7] Therefore, the present study was conducted to describe the perception and feedback regarding pathology as a subject among second-year (preclinical) medical students in an Indian medical college. The findings may suggest the need for revision of the current methods of teaching, learning and assessment.

\section{Methods}

This cross-sectional study was carried out on 145 out of a total of 150 second-year preclinical medical students sitting for their final professional exams at the Department of Pathology, Adesh Medical College and Hospital, Mohri, Shahbad (M), Kurukshetra, Haryana, India from September to October 2019. Students repeating the class were excluded from the study. Purposive sampling was used to select consenting students and the tenets of Helsinki's Declaration were adhered to during the study.

A pre-designed questionnaire with questions about students' perception of pathology was administered to the students. The questionnaire addressed students' perception of pathology as a subject, effectiveness of the various teachinglearning methods, methods of assessment and suggestions on the need for revision of the existing methods.

The questionnaire also tested views on the various teaching-learning methods like blackboard teaching, Powerpoint presentation, small group discussions, and tutorials currently used by the faculty. The validity of the questionnaire was determined by experts in the department while the reliability of the questionnaire was Cronbach alpha 0.76.

The data were analysed using simple descriptive statistics like frequencies and percentages.

\section{Results}

All the 145 medical students recruited into the study responded to the questionnaire. The subjects were aged 19-1 years with a mean of 20 years. The male-to-female ratio was 1.2:1.

Table I shows that the majority of the students (100; 68.9\%) reported pathology to be an interesting subject; $54.5 \%$ found systemic pathology tough while $55.9 \%$ found systemic pathology more interesting. One hundred and thirty-one (90.3\%) and 137 (90.5\%) of the students agreed that pathology acts as a bridge between preclinical and clinical medicine and also help them to understand clinical cases better respectively.

As shown in Table II, $86.2 \%$ of the students agreed that the lectures delivered were well organized and key points were adequately highlighted; $69.0 \%$ ) were satisfied with the pace of lectures while $24.1 \%$ were dissatisfied. Also, $49.6 \%$ agreed that the lectures encouraged adequate participation of the students. About teaching-learning methods, $73.8 \%$ ) regarded blackboard teaching as more effective as Powerpoint learning was monotonous with problems of file corruption, incompatible media, and equipment failure. Similarly, $85.5 \%$ of the students considered case-based discussions and histopathology light microscopy sessions to be more useful. 
Table I: Students' perception of pathology as a subject

\begin{tabular}{|c|c|c|c|}
\hline Items & Agreed & Disagreed & Did not know \\
\hline \multicolumn{4}{|l|}{ Do you find Pathology: } \\
\hline a. Interesting Subject & $100(68.9)$ & $20(13.7)$ & $25(17.2)$ \\
\hline b. Difficult Subject & $73(50.3)$ & $29(20.0)$ & $43(29.7)$ \\
\hline c. Challenging Subject & $78(55.8)$ & $18(12.4)$ & $49(33.8)$ \\
\hline \multicolumn{4}{|l|}{ Which aspect of pathology is tougher? } \\
\hline a. General Pathology & $23(15.9)$ & $42(28.9)$ & $80(55.2)$ \\
\hline b. Systemic Pathology & $79(54.5)$ & $26(17.9)$ & $40(27.6)$ \\
\hline c. Haematology & $61(42.0)$ & $22(15.2)$ & $65(44.8)$ \\
\hline d. Clinical pathology & $34(23.4)$ & $31(21.4)$ & $80(55.2)$ \\
\hline \multicolumn{4}{|l|}{ Which aspect of pathology do you find more interesting? } \\
\hline a. General Pathology & $62(42.8)$ & $25(17.2)$ & $58(40.0)$ \\
\hline b. Systemic Pathology & $81(55.9)$ & $15(10.3)$ & $49(33.8)$ \\
\hline c. Haematology & $29(20.0)$ & $30(20.7)$ & $86(59.3)$ \\
\hline d. Clinical pathology & $54(37.2)$ & $11(7.6)$ & $80(55.2)$ \\
\hline $\begin{array}{l}\text { Do you feel pathology is a bridge between } \\
\text { paraclinical and clinical branches? } \\
\text { Does pathology help to correlate with the clinical } \\
\text { cases? }\end{array}$ & $131(90.4)$ & $01(0.7)$ & $13(8.9)$ \\
\hline
\end{tabular}

Figures in parentheses are percentages of the total in each row

There were different methods employed for the assessment of the students. In Table III, 95.9\% agreed that written exams were an effective assessment tool; $90.4 \%$ of the students believed that regular class tests improve academic performance to a great extent. The other modes of assessment reported as useful in improving knowledge and application of skills included viva voce $(87.6 \%)$, case-based problems $(86.9 \%)$, practical examination and spotters $(84.1 \%)$.

Table IV depicts the different views and suggestions offered by the students concerning the current methods of teaching and learning. One hundred and seventeen $(80.7 \%)$ felt that there was a need for change in the present medical education system in India. Incorporation of web-based learning was favoured by $64.8 \%$ ) students; $82.1 \%$ agreed to the need to introduce MCQs and extended matching questions in the assessment method while $42.8 \%$ agreed with the need for OSCE and OSPE. The majority of the students $(127 ; 87.6 \%)$ reported that timely and practical feedback to students was a useful tool, followed by the introduction of handouts at the end of the session. Eighty per cent and $74.5 \%$ of the students believed in the introduction of research methodologies in the undergraduate curriculum. Only $57.3 \%$ of students found the need for buzz groups and one-minute preceptor relevant. 
Table II: Perceived effectiveness of various teaching-learning methods

\begin{tabular}{|c|c|c|c|}
\hline Content and quality & Agreed & Disagreed & Did not know \\
\hline Are the lectures well organized? & $125(86.2)$ & $16(11.0)$ & $04(2.8)$ \\
\hline $\begin{array}{l}\text { Do you feel that key points are adequately highlighted during the } \\
\text { lectures? }\end{array}$ & $125(86.2)$ & $09(6.2)$ & $11(7.6)$ \\
\hline Is the pace of the lectures easy to follow? & $100(69.0)$ & $35(24.1)$ & $10(6.9)$ \\
\hline Do the lectures encourage adequate student participation? & $72(49.6)$ & $49(33.8)$ & $24(16.6)$ \\
\hline \multicolumn{4}{|l|}{$\begin{array}{l}\text { Are the following kinds of teaching-learning methods useful for } \\
\text { learning and understanding pathology? }\end{array}$} \\
\hline a. Blackboard teaching & $107(73.8)$ & $18(12.4)$ & $20(13.8)$ \\
\hline b. Powerpoint presentations & $84(58.0)$ & $45(31.0)$ & $16(11.0)$ \\
\hline c. Case-based discussions & $124(85.5)$ & $12(8.3)$ & $09(6.2)$ \\
\hline d. Small group discussions & $93(64.1)$ & $25(17.2)$ & $27(18.7)$ \\
\hline e. Tutorials & $105(72.4)$ & $23(15.9)$ & 17 (11.7) \\
\hline f. Revision classes & $114(78.7)$ & $15(10.3)$ & $16(11.0)$ \\
\hline g. Self-directed learning & $106(73.1)$ & $16(11.0)$ & $23(15.9)$ \\
\hline h. Integrated Teaching & $90(62.1)$ & $12(8.3)$ & $43(29.6)$ \\
\hline i. Museum Teaching & $77(53.1)$ & $30(20.7)$ & $38(26.2)$ \\
\hline j. Seminars & $69(47.6)$ & $51(35.2)$ & $25(17.2)$ \\
\hline k. Histopathology light microscopy sessions & $124(85.5)$ & $07(4.8)$ & $14(9.7)$ \\
\hline
\end{tabular}

Figures in parentheses are percentages of the total in each row

Table III: Students' perception of the methods of assessment

\begin{tabular}{|c|c|c|c|c|}
\hline Items & & Agreed & Disagreed & Did not know \\
\hline \multicolumn{5}{|c|}{ Are the following methods of assessment helpful in improving knowledge and application skills? } \\
\hline a. & $\begin{array}{l}\text { Written exams (long essays and short answer } \\
\text { open-ended questions) }\end{array}$ & $139(95.9)$ & $02(1.4)$ & $04(2.7)$ \\
\hline b. & Practical examination & $122(84.1)$ & $08(5.5)$ & $15(10.4)$ \\
\hline$c$. & Viva voce & $127(87.6)$ & $14(9.7)$ & $04(2.7)$ \\
\hline d. & Case-based problems & $126(86.9)$ & $09(6.2)$ & $10(6.9)$ \\
\hline \multirow[t]{3}{*}{ e. } & (instruments/gross & $122(84.1)$ & $10(6.9)$ & $13(9.0)$ \\
\hline & specimens/histopathology & & & \\
\hline & slides/laboratory & & & \\
\hline f. & $\begin{array}{l}\text { interpretation of data } \\
\text { Regular class tests: Does it improves the } \\
\text { performance? }\end{array}$ & $131(90.4)$ & $07(4.8)$ & $07(4.8)$ \\
\hline
\end{tabular}

Figures in parentheses are percentages of the total in each row 
Table IV: Suggestions offered by the students

\begin{tabular}{|c|c|c|c|}
\hline Items & Agreed & Disagreed & Did not Know \\
\hline Is change needed in the present medical education system in India? & $117(80.7)$ & $07(4.8)$ & $21(14.5)$ \\
\hline $\begin{array}{l}\text { Will horizontal and vertical integration among the semesters help } \\
\text { in improving the clinical skills and application? }\end{array}$ & $110(75.9)$ & $09(6.2)$ & $26(17.9)$ \\
\hline Incorporation of web-based learning & $94(64.8)$ & $25(17.2)$ & $26(18.0)$ \\
\hline $\begin{array}{l}\text { Is there a need to introduce multiple choice questions and } \\
\text { Extended Matching Questions in the assessment method? }\end{array}$ & $119(82.1)$ & $14(9.7)$ & $12(8.2)$ \\
\hline Should OSCE and OSPE be introduced as assessment tools? & $62(42.8)$ & $10(6.9)$ & $73(50.3)$ \\
\hline $\begin{array}{l}\text { Do the methods of introduction of reflection writing by the } \\
\text { students help to bring about constructive improvement in students } \\
\text { as well teachers? }\end{array}$ & $96(66.2)$ & $08(5.5)$ & $41(28.3)$ \\
\hline Is there a need to give timely and practical feedback to students? & $127(87.6)$ & $06(4.1)$ & $12(8.3)$ \\
\hline $\begin{array}{l}\text { Is the introduction of research methodologies required in the } \\
\text { undergraduate curriculum? }\end{array}$ & $108(74.5)$ & $12(8.3)$ & 25 (17.2) \\
\hline $\begin{array}{l}\text { Are handouts, including exercises and questions and suggested } \\
\text { reading lists, required at the end of the session? }\end{array}$ & $116(80.0)$ & 05 (3.4) & 24 (16.6) \\
\hline $\begin{array}{l}\text { Is the introduction of buzz groups and a one-minute preceptor } \\
\text { needed? }\end{array}$ & $83(57.3)$ & 17 (11.7) & $45(31.0)$ \\
\hline
\end{tabular}

Figures in parentheses are percentages of the total in each row

OSCE - Objective Structured Clinical Examination; OSPE - Objective Structured Practical Examination

\section{Discussion}

The second-year preclinical class is a crucial period in undergraduate medical education because it is the period when the student is introduced to clinical postings and taught the aetiopathogenesis of various disease processes. [8] Shah et al. ${ }^{[8]}$ observed that $68.5 \%$ of students found pathology interesting and $86.6 \%$ felt that the knowledge of pathology helps in clinical posting similar to the finding in the present study where $68.9 \%$ also found pathology interesting. In the study by Goyal et al., [9] only $43 \%$ of the students found pathology interesting. This could be due to the degree of correlation of the aetiopathogenesis of diseases with the clinical signs and symptoms which the students encountered in their clinical rotations.

In another study by Integrated teaching refers to intercalation of the basic/preclinical subjects with the clinical subjects. This method of teaching is effective in enhancing the skill of clinicopathological correlation and it helps with improving the cognitive and psychomotor domains of the students. ${ }^{[2]}$ Shah et al had earlier reported that $84.2 \%$ of students agreed that integrated teaching is the most effective method of teaching that guarantees thorough understanding. ${ }^{[8]} \mathrm{A}$ similar finding was reported by Goyal et al. [9] and Kate et al. [10]

In the present study, about ninety per cent of students were satisfied with the clinical relevance and content of the lectures in pathology. Vijayan et al. [11] reported that $95 \%$ of students were satisfied with the clinical relevance whereas $76.6 \%$ of students were satisfied with the content of the lecture. In another study by Quadri, ${ }^{[3]}$ only $41.6 \%$ and $36.3 \%$ of the students were satisfied with the relevance and content of the lectures respectively. In the present study, the students reported that regular case-based problems being 
discussed in the theory classes and tutorials and correlating them with the clinical cases have provided a platform for better understanding and correlation during their clinical postings.

The majority of the students in the present study $(86.2 \%)$ believed that important points in the subject were adequately highlighted and explanations were satisfactorily provided to clarify the contents of the teachings whereas Vijayan et al., [11] reported a higher frequency $(93.3 \%)$. Over two-thirds of the students in the present study $(69.0 \%)$ were satisfied with the delivery and pace of lectures in agreement with the findings of Vijayan et al. [11] compared to $30.9 \%$ reported by Quadri et al. [3] It is important to state that at the location of the present study, the pace of delivery of teachings is maintained to make the subject interesting and more understandable.

In the present study, about half of the students agreed that they were encouraged to engage in "question and answer" sessions during lectures, similar to the finding of $40.1 \%$ by Quadri. [3] However, the frequency was higher $(76.6 \%)$ in the report of Vijayan et al. [11] This may be explained by the fact that students believed the traditional lectures were monotonous, continuous and difficult to concentrate on. They believed that interactions during teachings keep them active and more attentive, hence results in better understanding and more retention of the knowledge.

Among all the teaching-learning methods, a majority of the students preferred histopathology light microscopy sessions and case-based discussions in about eighty-five per cent in each case similar to the report by Shah et al. ${ }^{[8]}$ where $88.1 \%$ of students liked case-based learning. The students in the present study also preferred light microscopy as they believed it was more interesting, whereas case-based learning is perceived to have more relevance to the cases encountered during clinical postings. Emerald et al. [4] reported that $70 \%$ of students agreed that pathology is better understood with lectures combined with demonstrations using morbid specimens and microscopic slides. This observation leads to the upgrade of teaching facilities using an information-technology based system.

In the present study, blackboard teaching was preferred by $73.8 \%$ of students similar to $78.3 \%$ reported by Vijayan et al. [11] In another study by Sharma et al., [12] only $52.7 \%$ of students found learning to be more effective with the use of blackboard while $47.3 \%$ preferred teaching by Powerpoint presentations. This observation may be explained by the fact that students may prefer conventional teaching methods compared to Powerpoint teaching which may become monotonous and a one-way mode of communication.

Most of the students in the present study agreed that group discussions facilitated by the faculty, the use of integrated teachings and Powerpoint presentation teaching $(57.93 \%)$ are the most effective teaching-learning methods. This was similar to the report of Goyal et al., [9] that judicious use of audiovisual aids along with the conventional methods may be most desirable. The findings of many studies show that contemporary generations of medical students generally favour an integrated model of learning, where e-learning is combined with the traditional teaching methods, as a blended learning format. [13, 14] In a study done by Julio et al., [15] it was stated that an integrated curriculum utilizing information technology provides an excellent opportunity to relate pathology with clinical medicine, early in the training of medical students. Therefore, upgrading the teaching facilities towards information technology-based system could improve the teaching of pathology. [4] 
Assessment is considered the most important factor driving students' learning, as students tend to mainly focus on the materials on which assessment will be based. [11] Students believed that the assessment method should be mainly formative in type focusing on the process of learning and providing information about the improvement of knowledge and skills compared to the summative type of assessment which focuses on the outcome and provide information on attainment of knowledge and skills.[16]

In the present study, the majority of the students agreed that written exams, viva-voce and practical examinations were useful tools of assessment. This was similar to the findings in the study done by Vijayan et al. [11] Regular class tests were also found to improve academic performance similar to the report by Sharma et al. [12] Few students felt that assessment by viva voce and practical examinations provide a uniform, equitable and unbiased assessment of students. The majority $(82.1 \%)$ of the students believed in the need to introduce MCQs and extended matching questions as assessment methods as they are believed to improve preparations for the postgraduate entrance tests. This desirability of MCQ is similar to the finding of Goyal et al., [9] In the present study, less than half of the respondents believed in OSCE and OSPE as useful assessment tools perceived to be more useful as learning tools during pre-examination revision exercises. Goyal et al had suggested that there should be an increased emphasis on the incorporation of problem-based, contextual, selfdirected learning, role-play exercises and integrated teaching into the curriculum. This desired shift from the traditional approach of teaching and assessment to a need-based approach requires a fundamental change of the roles and commitments of educators, planners and policymakers. [9] Goyal et al, [9] also stated that information provided through the internet was confusing because most of the times they were not able to judge which piece of information was relevant whereas many students found online books and academic links quite useful and time-saving.

Feedback is also considered an important part of the assessment process. It should be constructive, timely and meaningful. In the present study, close to ninety per cent of students agreed that there is a need to give timely and practical feedback to students. Feedback encourages critical thinking and motivates one to reflect on what needs to be done to improve academic performance. It also guides the teachers to accommodate the learning needs of the students. It should reveal the format of grading to the students. In most medical schools, practical exercises are an integral part of the coursework in pathology hence the assessment of these practical exercises is important. [11]

\section{Conclusion}

This study revealed that most of the students found pathology interesting as a course of study with a general preference for integrated teaching methods with a focus on the traditional blackboard teaching method and MCQ, viva-voce and practical tests as useful assessment tools. Feedbacks from the students regarding pathology as a subject may help with upgrading and refinement. Therefore, upgrading the medical education system in India will enable students to acquire the requisite knowledge, ethics, communication skills, and help them to become better learners and professionals.

Authors' Contributions: GSP conceived and designed the study. SS did the literature review, data acquisition, data analysis and interpretation and drafted the manuscript. GSP revised the manuscript for sound intellectual contents. Both authors approved the final version of the manuscript.

Conflict of Interest: None.

Funding: Self-funded. 
Publication History: Submitted 18 February 2021; Accepted 25 April 2021.

\section{References}

1. Domizio P. The Changing role of pathology in the undergraduate curriculum. In: Hall PA, Wright NA (Editors). Understanding Disease: A centenary celebration of the Pathological Society, London: Wiley. 2006: p. 137-152.

2. Rafique N. Introducing integrated practical examination for second-year MBBS class. Proceedings in the 7th GCC Medical Colleges Conference by the Saudi Society of Family and Community Medicine 2009 Nov 17th19th. Dammam, Saudi Arabia.

3. Quadri SSS, Srujana S, Mahesh S, Bheeshma B. Undergraduate medical students' feedback and perceptions on teaching-learning methodology in Pathology at Government Medical College. Int Arch Integrated Med 2016; 3: 28-35.

4. Emerald NM, Han TZ, Oo SS. Students' perception on the effectiveness of pathology teaching in Phase 1 medical program at UCST university. Int J Med Sci Educ 2016; 3: 264-273.

5. Rahman N, Ferdousi S, Hoq N, Amin R, Kabir J. Evaluation of objective structured practical examination and traditional practical examination. Mymensingh Med J 2007; 16: 711. https:// doi.org/10.3329/mmj.v16i1.239

6. Clinical Pharmacology Section of Indian Pharmacological Society supported by WHO SEAR. MBBS curriculum review draft developed by core group for MBBS curriculum development (IPS members) at the National Consultative Meeting on review of pharmacology curriculum for UG and PG medical education in India with focus on better medicines for children. Kolkata. 2010 September 29-30th. Available from: URL: http://aimdda.wordpress.com/author/aim dda/
7. Gulikers J, Bastiaens T, Kirschner P, Kester L. Relations between student perceptions of assessment authenticity, study approaches and learning outcome. Studies Educ Evaluation 2006; 32: 381-400. https://doi.org/10.1016/j.stueduc.2006.10.0 $\underline{03}$

8. Shah A, Shethwala N, Parmar B. Perception of undergraduate medical students towards the subject of Pathology at one of the Medical Colleges of Gujarat, India. Int J Med Sci Public Health 2014; 3: 863-865. https://doi.org/10.5455/ijmsph.2014.140420 $\underline{142}$

9. Goyal M, Bansal M, Gupta A, Yadav D. Perceptions and suggestions of second professional MBBS students about their teaching and learning process: An analytical study. Nat J Integrated Res Med 2010; 1: 2024.

10. Kate MS, Kulkarni UJ, Supe A, Deshmukh YA. Introducing integrated teaching in undergraduate medical curriculum. Int J Pharma Sci Res 2010; 1(1): 18-22.

11. Vijayan P, Ponniah A. A survey study based on undergraduate medical students' feedback regarding pathology and the teachinglearning methodologies employed. Trop J Path Micro 2017; 3: 149-154. https://doi.org/10.17511/jopm.2017.i2.14

12. Sharma P, Singh P, Kalhan S, Garg S. Analysis of factors affecting academic performance of MBBS Students in pathology. Ann Int Med Den Res 2017; 3: PT09-PT15. https://doi.org/10.21276/aimdr.2017.3.5.PT $\underline{4}$

13. Woltering V, Herrler A, Spitzer K, Spreckelsen C. Blended learning positively affects students' satisfaction and the role of the tutor in the problem-based learning process: results of a mixed-method evaluation. Adv Health Sci Educ Theory Pract 2009; $\quad$ 14: 725-738. https:// doi.org/10.1007/s10459-009-9154-6 
14. Gray $\mathrm{K}$, Tobin J. Introducing an online community into a clinical education setting: a pilot study of student and staff engagement and outcomes using blended learning. BMC

Med Educ 2010; 10: 6.

https://doi.org/10.1186/1472-6920-10-6

15. Daiz-Perez JA, Raju S, Julio ADP, Sharat R, Echeverri JH. Evaluation of a teaching strategy based on the integration of clinical subjects, virtual autopsy, pathology museum, and digital microscopy for medical students. J Pathol Inform 2014; 5: 25. https://doi.org/10.4103/2153-3539.137729

16. Regulations on Graduate Medical Education (Amendment), 2019. No. MCI-34(41)/2019Med./161726. November 4, 2019; Part III-Sec. 4:59. source is adequately cited and credited. 